\title{
Serum Adiponectin Levels in Advanced-Stage Parkinson's Disease Patients
}

\section{Erica Cassani, ${ }^{1}$ Raffaella Cancello, ${ }^{1,2}$ Ferruccio Cavanna, ${ }^{1,3}$ Sabrina Maestrini, ${ }^{2}$ Anna Maria Di Blasio, ${ }^{2}$ Antonio Liuzzi, ${ }^{2}$ Gianni Pezzoli, ${ }^{1}$ and Michela Barichella ${ }^{1}$}

${ }^{1}$ Parkinson Institute, Istituti Clinici di Perfezionamento (ICP), via Bignami 1, 20126 Milan, Italy

${ }^{2}$ Istituto Auxologico Italiano, via Zucchi 18, 20095 Cusano Milanino, Milan, Italy

${ }^{3}$ Centro Analisi Monza (CAM), via Missori 9, 20052 Monza, Italy

Correspondence should be addressed to Erica Cassani, erica.x@libero.it

Received 10 January 2011; Revised 21 March 2011; Accepted 24 April 2011

Academic Editor: Francisco Grandas

Copyright (๑) 2011 Erica Cassani et al. This is an open access article distributed under the Creative Commons Attribution License, which permits unrestricted use, distribution, and reproduction in any medium, provided the original work is properly cited.

\begin{abstract}
Patients with advanced Parkinson's disease (PD) experience body weight loss and reductions in the most common cardiovascular risk factors. At present, the pathogenetic mechanisms involved have not been elucidated. Increased serum concentrations of adiponectin, which possesses antiatherogenic and anti-inflammatory properties, are associated with a reduction in cardiovascular risk. The objective of this study was to determine adiponectin serum concentrations in PD patients. Thirty PD patients underwent a full nutritional status assessment, including the determination of adiponectin serum concentrations. Mean \pm SD adiponectin concentrations were $9.59 \pm 5.9 \mu \mathrm{g} / \mathrm{mL}$ (interquartile range: $5.92-12.9 \mu \mathrm{g} / \mathrm{mL}$ ). In PD patients, adiponectin serum levels were similar to those in normal-weight, healthy, young subjects and significantly higher than that in an aged-matched group of morbidly obese subjects. Further studies are warranted to establish the role of adiponectin in the management of PD patients.
\end{abstract}

\section{Introduction}

Patients with Parkinson's disease (PD) experience weight loss in the advanced stages of the disease, resulting in a reduction in body mass index (BMI) [1-3]. Weight loss appears to involve mainly adipose tissue and to spare (or even increase) fat-free mass $[4,5]$ although not all findings reported in the literature are consistent with this conclusion [6].

Reductions in the most common cardiovascular risk factors (elevated concentrations of fasting glucose, LDL cholesterol, triglycerides, and arterial hypertension) have been recorded in PD patients $[7,8]$ as well as an improvement in HDL cholesterol [9]. The pathogenetic mechanisms involved have not been elucidated. According to some authors, the phenomenon may be induced by the modulating activity of levodopa therapy on the sympathetic system [10].

It has been shown that there is a relationship between adipose tissue and cardiovascular risk mediated by adipokines, such as adiponectin. Adiponectin is a protein synthesized by white fat tissue, whose concentrations in human serum range from 3 to $30 \mu \mathrm{g} / \mathrm{mL}$ [11-14]. High serum adiponectin concentrations, which are influenced by a reduction in fat mass [11], are associated with a reduction in the risk of myocardial infarction, even after adjustment for HDL, LDL, and BMI levels [15], whereas low-adiponectin concentrations are associated with the risk of developing type II diabetes [16] and hypertension [17]. It is well known that adiponectin exerts important vascular and cardiac effects, especially in preserving endothelial function, protecting it from ischemic and reperfusion damage, and in stimulating angiogenesis; it also possesses anti-inflammatory, antiapoptotic and antihypertrophic properties [18]. Furthermore, it modulates inflammation, reducing the synthesis of proinflammatory cytokines, such as TNF $\alpha$ [19]. Overall, it, therefore, appears that adiponectin has antiatherogenic effects that could explain how it is able to reduce cardiovascular risk.

To date, the data reported in the literature on adiponectin concentrations are related to the general population or to subjects with different degrees of obesity, diabetes, and/or dyslipidemia. To our knowledge, no data in PD patients exist. 
The objective of our study was to determine serum adiponectin concentrations in a group of PD patients in advanced stages of the disease $[20,21]$, to assess whether there is a correlation between adiponectin concentrations, body composition, and metabolic markers in this patient population.

\section{Materials and Methods}

2.1. Study Population. We recruited 30 patients suffering from PD admitted to the Parkinson Institute (Istituti Clinici di Perfezionamento (ICP) Hospital, Milan, Italy) consecutively. PD was diagnosed according to UK Brain Bank criteria [22]. All enrolled patients were on treatment with levodopa and a dopamine agonist for neurological symptoms. No patients were on treatment prescribed to decrease total cholesterol levels. Patients had a mean duration of PD of 8.7 \pm 6.1 years (range $5-20$ years).

Twenty-eight morbidly obese subjects (14 males, 14 females; mean \pm SD age $68.4 \pm 11$ years, mean \pm SD body mass index (BMI, $\left.\mathrm{kg} / \mathrm{m}^{2}\right) 43.5 \pm 5.3$ ) were enrolled in the study. Due to the higher degree of obesity, some of the obese patients were in treatment with lipid-lowering drugs. Blood samples were obtained in the morning, after an overnight fast.

Thirty-three (22 males and 11 females) normal-weight (BMI $22.9 \pm 2$ ), metabolically healthy volunteers, aged $36 \pm$ 6 years, were also enrolled. In this latter group, arterial pressure was assessed, and it was in the normality range for all subjects. They were not on treatment prescribed to decrease total cholesterol levels. They had normal glucose, total cholesterol, and insuline levels. Blood samples were obtained in the morning, after an overnight fast.

2.2. Assessments. All patients underwent assessment of nutritional status.

The nutritional assessments included the following steps:

(i) complete nutritional examination (family history, lifestyle, medical history including pharmacological treatment, dietary history, body weight history, and assessment of any complication of nutritional interest);

(ii) body composition evaluation by anthropometric methods (described in the following section);

(iii) assessment of nutritional status by measuring biochemical parameters and adiponectin serum level quantification.

During the hospital stay, the patients underwent also a neurological examination designed to fine-tune the diagnosis and adjust treatment accordingly.

The anthropometric assessment included measurement of body weight, height and calculation of body mass index (BMI) and of the main body circumferences (waist at the anterior superior iliac crest and arm).

Venous blood sampling was carried out in the morning, after an overnight fast, for the following laboratory tests: (i) routine tests: total cholesterol, HDL cholesterol, creatinine, transaminases, blood glucose, triglycerides, and uric acid;

(ii) indicators of nutritional status: plasma transferrin, albumin, and total lymphocytes.

The analyses were carried out at the Laboratory of ICP Hospital, according to standard methods.

Total adiponectin levels in serum were determined by an enzyme-linked immunoabsorbent assay (ELISA Total Human Adiponectin Kit, TECOmedical GROUP, Sissach, Switzerland). Total adiponectin detection limit was 1.56$100 \mathrm{ng} / \mathrm{mL}$.

2.3. Statistical Analysis. Patients involved in the study were numbered progressively, and the relative anonymous data were used for the creation of a database protected by password. The following variables were collected: body weight $(\mathrm{kg})$, height (meters), BMI $\left(\mathrm{Kg} / \mathrm{m}^{2}\right)$, waist circumference $(\mathrm{cm})$, arm circumference $(\mathrm{cm})$, blood glucose $(\mathrm{mg} / \mathrm{dL})$, total cholesterol $(\mathrm{mg} / \mathrm{dL})$, HDL cholesterol $(\mathrm{mg} / \mathrm{dL})$, triglycerides $(\mathrm{mg} / \mathrm{dL})$, creatinine $(\mathrm{mg} / \mathrm{dL})$, albumin $(\mathrm{g} / \mathrm{dL})$, transferrin (mg/dL), AST (U/L), ALT (U/L), duration of disease (years), daily intake of levodopa $(\mathrm{mg})$, and adiponectin $(\mu \mathrm{g} / \mathrm{mL})$.

A Shapiro-Wilk W-test was performed systematically to test the normality of data distribution. In case of lack of normality, data were log-transformed. The statistical analysis of data was carried out using JMP software, version 3.2.6, SAS Institute Inc, USA. A $P$-value $<.05$ was the set limit for statistical significance. Means were compared using ANOVA/Student's $t$-test, and Pearson's test was used to assess correlations between two variables at a time. The patient population was subdivided into two groups according to whether their HDL cholesterol was above or below the threshold for protection against cardiovascular disease: $\geq 50 \mathrm{mg} / \mathrm{dL}$ (PD HDL-high group) and $<50 \mathrm{mg} / \mathrm{dL}$ (PD HDL-low group). To analyze this comparison, Wilcoxon test (for non parametric data) and/or ANOVA test were used.

\section{Results}

The biochemical and clinical features of the studied PD patients are summarized in Table 1. Most of the patients were males $(64 \%)$. No differences between genders were recorded, except for an anthropometric parameter, such as waist circumference $(P=.02)$ and fat mass/fat-free mass percentage $(P<.05)$, as expected. Adiponectin serum concentrations in PD patients were on average $9.59 \pm$ $5.9 \mu \mathrm{g} / \mathrm{mL}$ (mean $\pm \mathrm{SD}$ ) with an interquartile range of 5.92 $12.9 \mu \mathrm{g} / \mathrm{mL}$.

In $\mathrm{PD}$ patients, the adiponectin serum levels were similar to adiponectin serum levels in normal-weight, healthy subjects $(9.02 \pm 6.7 \mu \mathrm{g} / \mathrm{mL})$ but significantly higher than those recorded in an aged-matched group of morbidly obese subjects $(6 \pm 2.9 \mu \mathrm{g} / \mathrm{mL})$, as shown in Figure 1(a). In PD patients, a significant positive correlation was found between serum adiponectin and HDL cholesterol concentrations (Figure 1(b)) (Rho $=0.53, P=.003$ ) which remained significant even after adjustment for gender, age, 


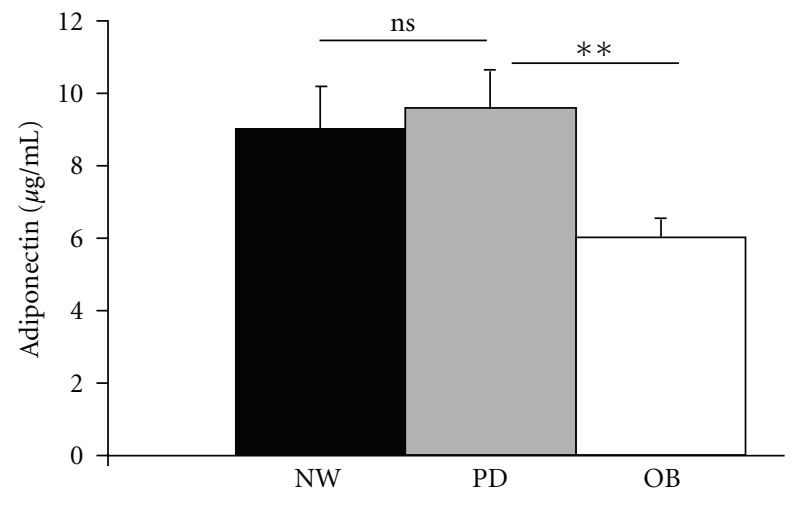

(a)

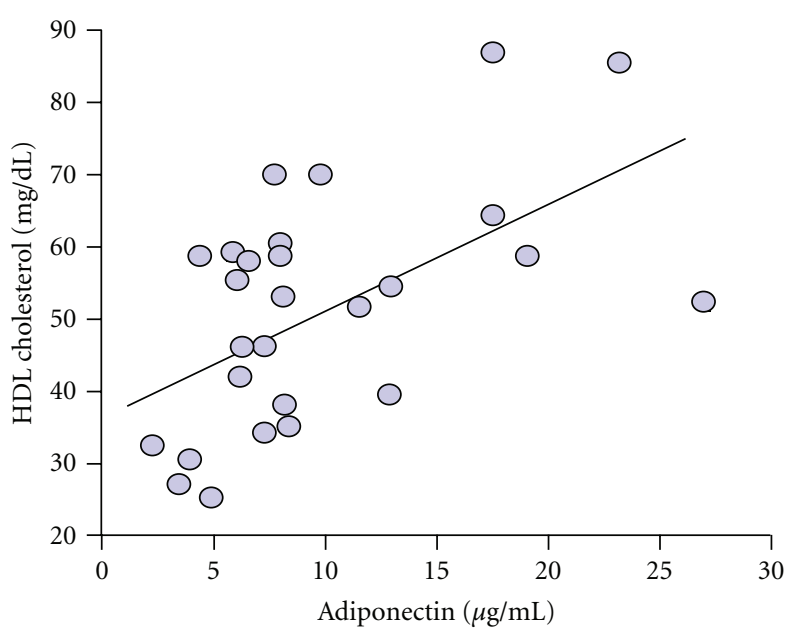

(b)

Figure 1: (a) adiponectin serum levels $(\mu \mathrm{g} / \mathrm{mL})$ in normal-weight $\mathrm{PD}$ and $\mathrm{OB}$ subjects. Mean $\pm \mathrm{SD}$, are shown. ${ }^{* *} P$-value $<.01$. (b) correlation between adiponectin serum levels $(\mu \mathrm{g} / \mathrm{mL})$ and HDL cholesterol levels $(\mathrm{mg} / \mathrm{dL})$ in PD patients $(n=30)(\mathrm{Rho}=0.53, P=.003)$.

TABLE 1: Biochemical, anthropometric, and clinical characteristics of the Parkinson disease (PD) patient population enrolled, $n=30$, $\mathrm{M} / \mathrm{F}=19(64 \%) / 11(36 \%)$. Data are expressed as mean $\pm \mathrm{SD}$.

\begin{tabular}{lc}
\hline Parameter & Data (mean \pm standard deviation) \\
\hline Age $($ years $)$ & $62.4 \pm 10.63$ \\
Duration of disease (years) & $8.7 \pm 6.1$ \\
Levodopa $(\mathrm{mg})$ & $532.7 \pm 220.1$ \\
BMI $\left(\mathrm{Kg} / \mathrm{m}^{2}\right)$ & $25.5 \pm 4.2$ \\
Weight $(\mathrm{Kg})$ & $71.8 \pm 15.7$ \\
Waist circumference $(\mathrm{cm})$ & $95.23 \pm 15.8$ \\
Arm circumference $(\mathrm{cm})$ & $28.4 \pm 3.97$ \\
Fat mass $(\%)$ & $32.3 \pm 7.74$ \\
Fat-free mass $(\%)$ & $67.7 \pm 6.7$ \\
Albumin $(\mathrm{g} / \mathrm{dL})$ & $3.89 \pm 0.2$ \\
Transferrin $(\mathrm{mg} / \mathrm{dL})$ & $243.6 \pm 40.5$ \\
Creatinine $(\mathrm{mg} / \mathrm{dL})$ & $0.67 \pm 0.1$ \\
ALT $(\mathrm{U} / \mathrm{L})$ & $13.5 \pm 6.6$ \\
AST $(\mathrm{U} / \mathrm{L})$ & $16.8 \pm 4.9$ \\
Triglycerides $(\mathrm{mg} / \mathrm{dL})$ & $97.5 \pm 46.3$ \\
Glucose $(\mathrm{mg} / \mathrm{dL})$ & $87.5 \pm 14.9$ \\
Total cholesterol $(\mathrm{mg} / \mathrm{dL})$ & $189.0 \pm 46.21$ \\
HDL cholesterol $(\mathrm{mg} / \mathrm{dL})$ & $51.8 \pm 16.4$ \\
Adiponectin $(\mu \mathrm{g} / \mathrm{mL})$ & $9.59 \pm 5.97$ \\
\hline
\end{tabular}

and duration of disease. In the PD patient group, there was an inverse correlation between adiponectin serum levels and waist circumference (Rho $=-0.37, P=.05$ ), body weight (Rho $=-0.47, P=.009$ ), fasting glucose concentrations (Rho $=-0.47, P=.01$ ), and triglyceride concentrations (Rho $=-0.48, P=.01)$. No correlation was observed between adiponectin serum levels and BMI, nor between adiponectin and fat mass fat-free mass percentage.

The association between high levels of HDL cholesterol and a decreased risk for cardiovascular disease has been well established through epidemiological and clinical studies. We then decided to analyze our patients regrouped for HDL cholesterol levels: patients with $\mathrm{HDL} \geq 50 \mathrm{mg} / \mathrm{dL}$ were in the PD HDL-high group while patients with $\mathrm{HDL}<50 \mathrm{mg} / \mathrm{dL}$ were in the PD HDL-low group. Sixteen PD patients belonged to the PD HDL-high group ( $\mathrm{HDL} \geq 50 \mathrm{mg} / \mathrm{dL}$ ) and 14 to the PD HDL-low group ( $\mathrm{HDL}<50 \mathrm{mg} / \mathrm{dL}$ ). These two subgroups did not differ in terms of age, duration of disease, levodopa dosage, and total cholesterol concentrations. Serum adiponectin concentrations were significantly higher in the PD HDL-high group $(P=.02)$, and BMI, body weight, and fasting glucose levels were significantly lower in the PD HDLhigh group (Figure 2).

\section{Discussion}

The adiponectin serum levels in PD patients were similar to the adiponectin serum levels in young, healthy, normalweight subjects matched for BMI. Moreover, a correlation between adiponectin serum levels and HDL cholesterol concentrations was found. The finding of a direct correlation between adiponectin and HDL cholesterol concentrations is consistent with the known antiatherogenic properties of adiponectin protein [18]. Low levels of adiponectin are associated with low levels of HDL cholesterol and this combination might be an independent cardiovascular risk factor; on the other hand, high levels of adiponectin are associated with high levels of HDL cholesterol indicating protection against cardiovascular events. The growing body of data suggests that adiponectin reduces cardiovascular risk in the general population, that is, the risk of developing type II diabetes, hypertension, and myocardial infarction [15-17]. To our knowledge, this is the first study in which adiponectin serum levels have been measured in PD patients. There is some evidence suggesting that PD patients body weight is lower than age-matched healthy subjects [2]. We then decided to compare adiponectin levels in PD 


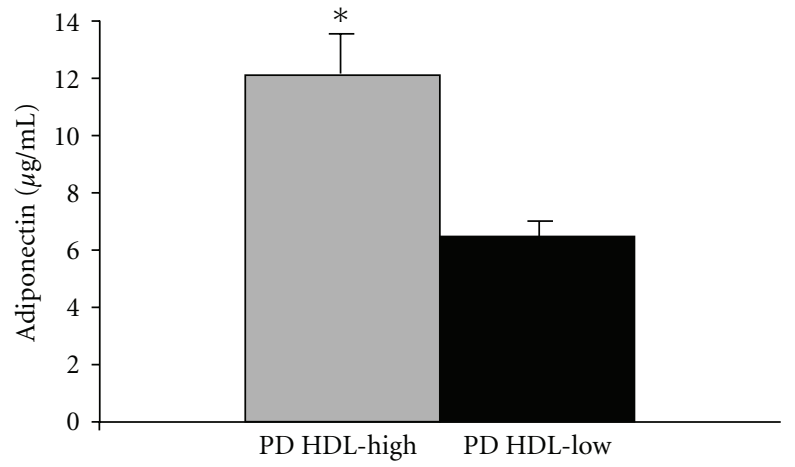

(a)

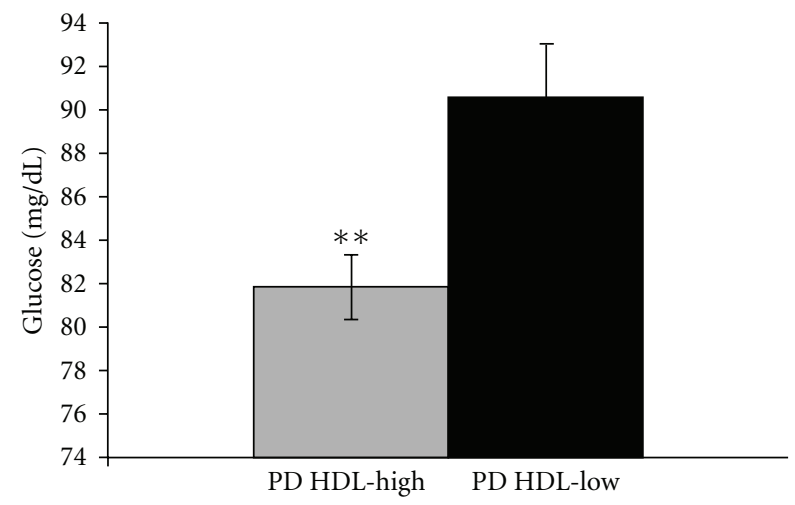

(c)

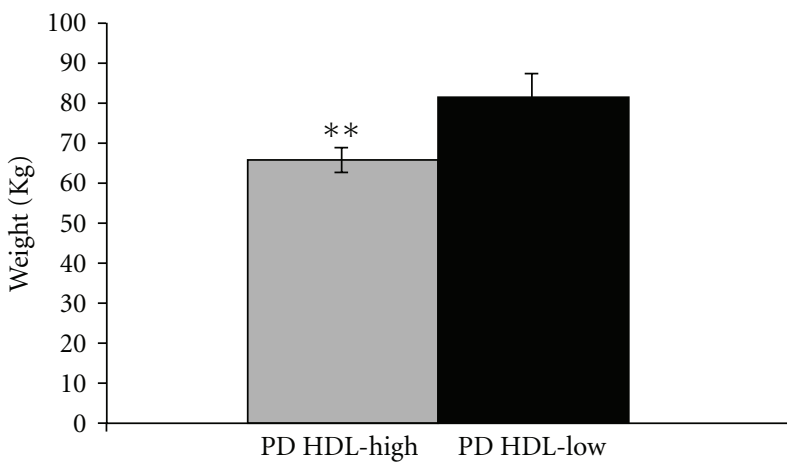

(b)

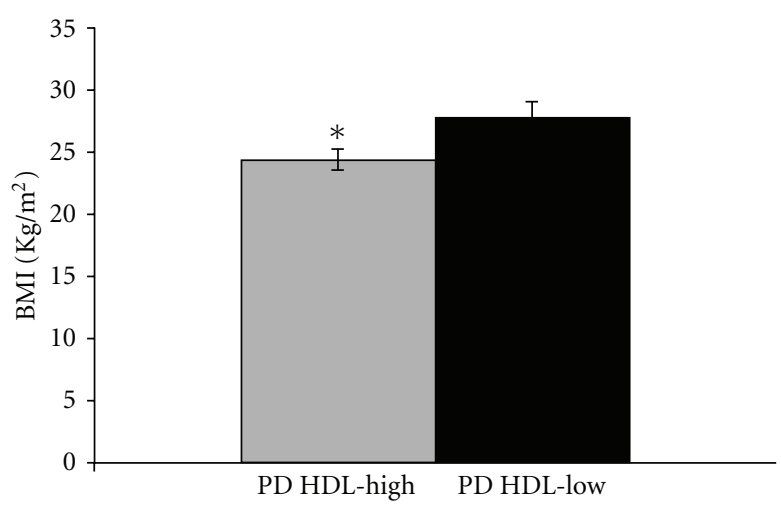

(d)

FIGURE 2: PD patient $(n=30)$ subgroups based on HDL cholesterol levels: PD HDL-high (HDL cholesterol $\geq 50 \mathrm{mg} / \mathrm{mL}, n=16)$ and PD HDL-low (HDL cholesterol $<50 \mathrm{mg} / \mathrm{mL}, n=14)$. Significant differences in means $( \pm \mathrm{SD})$ for adiponectin $(\mu \mathrm{g} / \mathrm{mL})$, fasting glucose $(\mathrm{mg} / \mathrm{dL})$, body weight $(\mathrm{kg})$, and BMI $\left(\mathrm{kg} / \mathrm{m}^{2}\right)$ are shown. ${ }^{*} P$-value $<.05 ;{ }^{* *} P$-value $<.01$.

patients with a BMI-matched group, despite a significant difference in mean age. Interestingly, adiponectin serum levels were not different in the two groups taken into consideration, indicating that adiponectin might play a role as a protective factor against cardiovascular disease also in PD patients. Previous studies were performed in the general population, focusing on differences between obese and nonobese subjects, and between genders. It has been established that in the general population, the synthesis of adiponectin is stimulated when the quantity of adipose tissue diminishes [23], contrary to most other adipokines, whose synthesis is directly proportional to the increase in fat mass. To date, the normal range for adiponectin serum levels has not been established. The mean value of serum adiponectin concentrations in nonobese subjects is about $10 \mu \mathrm{g} / \mathrm{mL}$; concentrations are lower by more than $50 \%$ in obese subjects [24, 25], taking into account differences linked to genders. We decided to compare adiponectin levels in a morbidly obese patient group, age-matched with the PD group. We observed that adiponectin levels in obese subjects were significantly decreased. Obesity is one of the first cardiovascular risk factors, and the reduction in adiponectin levels may have a role in this increased risk.

It is known that adiponectin serum concentrations differ between genders: in nonobese subjects, mean serum levels in men are lower than that in women $(7.7 \pm 3.1$ versus 10.6 $\pm 7.3 \mu \mathrm{g} / \mathrm{mL}$ ). This difference between genders may be due to androgen effects [26], which occur also in obese subjects [24]. A larger group is needed to address this issue in PD patients.

In the present study, we performed a comparison for adiponectin levels in PD patients with the levels of an agematched group of obese patients on one hand and with the circulating levels of a BMI-matched healthy control group on the other hand. Since adiponectin is decreased in obesity, in the comparison with PD patients, adiponectin levels of PD patients were as expected increased.

However, the levels in PD patients were not different when compared to healthy and young controls. With this kind of comparison it is hard to know whether the high adiponectin levels in PD patients are simply a reflection of body weight and body composition, or are intrinsically different in PD subjects. A future study, in a bigger cohort, both age- and BMI- matched, is needed to clarify this issue.

One issue in research on adiponectin is what form to measure in the bloodstream. In human serum, it occurs in the form of various oligomers: trimer, hexamer, and high molecular weight forms $[27,28]$. Both biological activity and the translation mechanism differ from multimer to multimer, but it has been shown beyond doubt that the active form is the high molecular weight adiponectin $[29,30]$. Much more work is required to establish which isoforms 
of adiponectin are associated with cardioprotection and to clarify the transduction mechanisms of receptor-mediated signals.

The clinical usefulness of adiponectin as a diagnostic/ prognostic marker has yet to be established according to the outcome of prospective clinical trials. In particular, information is needed on the predictive value of adiponectin serum concentrations as compared to other well-known risk factors. Thus, it is too early to propose the introduction of adiponectin serum concentrations as a biomarker in clinical practice. However, this adipokine appears to be an important factor to study not only as a potential diagnostic index for cardiovascular risk, but also as a target for pharmacological therapy [31].

The correlation we found between adiponectin and HDL cholesterol suggests that cardiovascular risk is low in $\mathrm{PD}$ patients. In a previous study, we observed a correlation between the duration of disease and HDL cholesterol concentrations [9]. The lower limit of normal for HDL cholesterol serum concentrations is usually considered $50 \mathrm{mg} / \mathrm{dL}$ [32]. For this reason, we decided to subdivide our patient population into two groups according to this cut-off value, which separated patients with normal values (PD HDL-high) from those with lower abnormal values (PD HDL-low). PD patients with HDL cholesterol $\geq 50 \mathrm{mg} / \mathrm{dL}$ resulted to have better metabolic protection (and higher adiponectin levels) as well as normal BMI and fasting glucose levels. High-density lipoprotein (HDL) cholesterol is a common and independent protective cardiovascular risk factor. Cardiovascular risk increases as HDL cholesterol levels decrease. While lipid lowering and antidiabetic drugs, such as statins, fibrates, and PPAR gamma agonists as well as diet alone have only marginal effects on HDL cholesterol serum levels. On the contrary, physical exercise is able to elevate HDL levels effectively.

\section{Conclusions}

In conclusion, this is the first study that shows that PD patients have serum adiponectin concentrations elevated and comparable to the levels of young normal-weight subjects with absence of cardiovascular risk factors. Moreover, the adiponectin concentrations are related to HDL cholesterol levels.

\section{Acknowledgments}

The authors express their gratitude to Jennifer S. Hartwig, $\mathrm{MD}$, for assistance in drafting the paper and to the "Fondazione Grigioni per il Parkinson" for financial support.

\section{References}

[1] H. Chen, S. M. Zhang, M. A. Hernán, W. C. Willett, and A. Ascherio, "Weight loss in Parkinson's disease," Annals of Neurology, vol. 53, no. 5, pp. 676-679, 2003.

[2] C. G. Bachmann and C. Trenkwalde, "Body weight in patients with Parkinson's disease," Movement Disorders, vol. 21, no. 11, pp. 1824-1830, 2006.
[3] K. Kashihara, "Weight loss in Parkinson's disease," Journal of Neurology, vol. 253, supplement 7, pp. VII38-VII41, 2006.

[4] H. S. Markus, A. M. Tomkins, and G. M. Stern, "Increased prevalence of undernutrition in Parkinson's disease and its relationship to clinical disease parameters," Journal of Neural Transmission-Parkinson's Disease and Dementia Section, vol. 5, no. 2, pp. 117-125, 1993.

[5] H. S. Markus, M. Cox, and A. M. Tomkins, "Raised resting energy expenditure in Parkinson's disease and its relationship to muscle rigidity," Clinical Science, vol. 83, no. 2, pp. 199-204, 1992.

[6] M. L. Petroni, G. Albani, V. Bicchiega et al., "Body composition in advanced-stage Parkinson's disease," Acta Diabetologica, vol. 40, supplement 1, pp. S187-S190, 2003.

[7] G. Scigliano, G. Ronchetti, and F. Girotti, "Autonomic nervous system and risk factors for vascular disease. Effects of autonomic unbalance in schizophrenia and Parkinson's disease," Neurological Sciences, vol. 29, no. 1, pp. 15-21, 2008.

[8] G. Scigliano, M. Musicco, P. Soliveri, I. Piccolo, G. Ronchetti, and F. Girotti, "Reduced risk factors for vascular disorders in Parkinson disease patients: a case-control study," Stroke, vol. 37, no. 5, pp. 1184-1188, 2006.

[9] E. Cassani, M. Barichella, C. Madio et al., "Body fat loss and HDL cholesterol improvement in advanced stages of Parkinson's disease," Movement Disorders, vol. 25, no. 3, p. S655, 2010.

[10] G. Scigliano, G. Ronchetti, F. Girotti, and M. Musicco, "Sympathetic modulation by levodopa reduces vascular risk factors in Parkinson disease," Parkinsonism and Related Disorders, vol. 15, no. 2, pp. 138-143, 2009.

[11] R. Shibata, N. Ouchi, and T. Murohara, "Adiponectin and cardiovascular disease," Circulation Journal, vol. 73, no. 4, pp. 608-614, 2009.

[12] E. Hu, P. Liang, and B. M. Spiegelman, "AdipoQ is a novel adipose-specific gene dysregulated in obesity," Journal of Biological Chemistry, vol. 271, no. 18, pp. 10697-10703, 1996.

[13] K. Maeda, K. Okubo, I. Shimomura, T. Funahashi, Y. Matsuzawa, and K. Matsubara, "cDNA cloning and expression of a novel adipose specific collagen-like factor, apM1 (AdiPose Most abundant Gene transcript 1)," Biochemical and Biophysical Research Communications, vol. 221, no. 2, pp. 286-289, 1996.

[14] P. E. Scherer, S. Williams, M. Fogliano, G. Baldini, and H. F. Lodish, "A novel serum protein similar to $\mathrm{C} 1 \mathrm{q}$, produced exclusively in adipocytes," Journal of Biological Chemistry, vol. 270, no. 45, pp. 26746-26749, 1995.

[15] T. Pischon, C. J. Girman, G. S. Hotamisligil, N. Rifai, F. B. $\mathrm{Hu}$, and E. B. Rimm, "Plasma adiponectin levels and risk of myocardial infarction in men," Journal of the American Medical Association, vol. 291, no. 14, pp. 1730-1737, 2004.

[16] J. Spranger, A. Kroke, M. Möhlig et al., "Adiponectin and protection against type 2 diabetes mellitus," The Lancet, vol. 361, no. 9353, pp. 226-228, 2003.

[17] Y. Iwashima, T. Katsuya, K. Ishikawa et al., "Hypoadiponectinemia is an independent risk factor for hypertension," Hypertension, vol. 43, no. 6, pp. 1318-1323, 2004.

[18] N. Ouchi, H. Kobayashi, S. Kihara et al., "Adiponectin stimulates angiogenesis by promoting cross-talk between AMPactivated protein kinase and Akt signaling in endothelial cells," Journal of Biological Chemistry, vol. 279, no. 2, pp. 1304-1309, 2004. 
[19] Y. Takemura, N. Ouchi, R. Shibata et al., "Adiponectin modulates inflammatory reactions via calreticulin receptordependent clearance of early apoptotic bodies," Journal of Clinical Investigation, vol. 117, no. 2, pp. 375-386, 2007.

[20] M. Barichella, E. Cereda, and G. Pezzoli, "Major nutritional issues in the management of Parkinson's disease," Movement Disorders, vol. 24, no. 13, pp. 1881-1892, 2009.

[21] E. Cereda, M. Barichella, C. Pedrolli, and G. Pezzoli, "Low protein and protein redistribution diets for Parkinson's disease patients with motor fluctuations: a sistematic review," Movement Disorders, vol. 25, no. 13, pp. 2021-2034, 2010.

[22] A. J. Hughes, Y. Ben-Shlomo, S. E. Daniel, and A. J. Lees, "What features improve the accuracy of clinical diagnosis in Parkinson's disease: a clinicopathologic study. 1992," Neurology, vol. 57, no. 10, pp. S34-S38, 2001.

[23] M. Ryo, T. Nakamura, S. Kihara et al., "Adiponectin as a biomarker of the metabolic syndrome," Circulation Journal, vol. 68, no. 11, pp. 975-981, 2004.

[24] Y. Arita, S. Kihara, N. Ouchi et al., "Paradoxical decrease of an adipose-specific protein, adiponectin, in obesity," Biochemical and Biophysical Research Communications, vol. 257, no. 1, pp. 79-83, 1999.

[25] M. Cnop, P. J. Havel, K. M. Utzschneider et al., "Relationship of adiponectin to body fat distribution, insulin sensitivity and plasma lipoproteins: evidence for independent roles of age and sex," Diabetologia, vol. 46, no. 4, pp. 459-469, 2003.

[26] H. Nishizawa, I. Shimomura, K. Kishida et al., "Androgens decrease plasma adiponectin, an insulin-sensitizing adipocyte-derived protein," Diabetes, vol. 51, no. 9, pp. 27342741, 2002.

[27] K. Kishida, H. Nagaretani, H. Kondo et al., "Disturbed secretion of mutant adiponectin associated with the metabolic syndrome," Biochemical and Biophysical Research Communications, vol. 306, no. 1, pp. 286-292, 2003.

[28] U. B. Pajvani, X. Du, T. P. Combs et al., "Structure-function studies of the adipocyte-secreted hormone Acrp30/ adiponectin. Implications for metabolic regulation and bioactivity," Journal of Biological Chemistry, vol. 278, no. 11, pp. 9073-9085, 2003.

[29] U. B. Pajvani, M. Hawkins, T. P. Combs et al., "Complex distribution, not absolute amount of adiponectin, correlates with thiazolidinedione-mediated improvement in insulin sensitivity," Journal of Biological Chemistry, vol. 279, no. 13, pp. 12152-12162, 2004.

[30] J. Tonelli, W. Li, P. Kishore et al., "Mechanisms of early insulinsensitizing effects of thiazolidinediones in type 2 diabetes," Diabetes, vol. 53, pp. 1621-1629, 2004.

[31] A. J. Walkey, T. W. Rice, J. Konter et al., "Plasma adiponectin and mortality in critically ill subjects with acute respiratory failure," Critical Care Medicine, vol. 38, no. 12, pp. 2329-2334, 2010.

[32] "Executive summary of the third report of the National Cholesterol Education Program (NCEP) expert panel on detection, evaluation, and treatment of high blood cholesterol in adults (adult treatment panel III)," Journal of the American Medical Association, vol. 285, no. 19, pp. 2486-2497, 2001, Expert Panel on Detection, Evaluation, and Treatment of High Blood Cholesterol in Adults. 


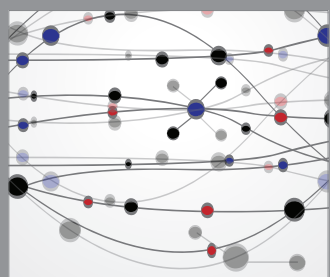

The Scientific World Journal
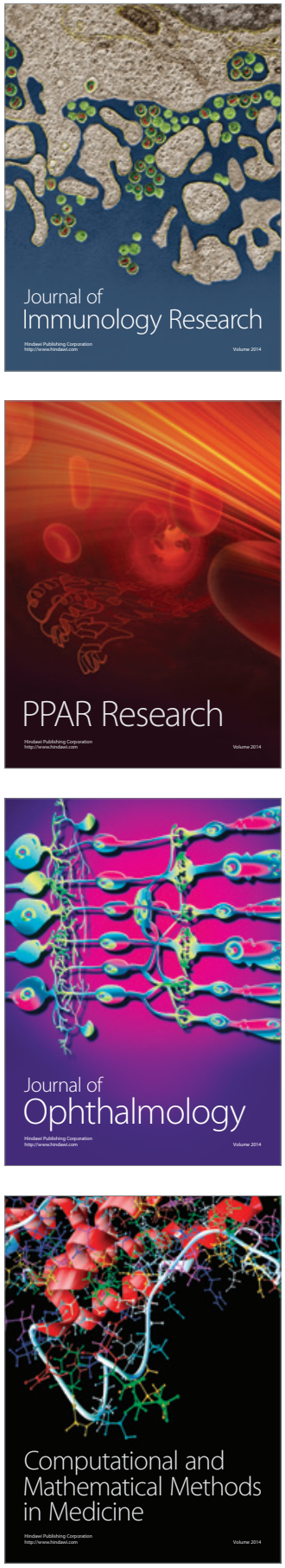

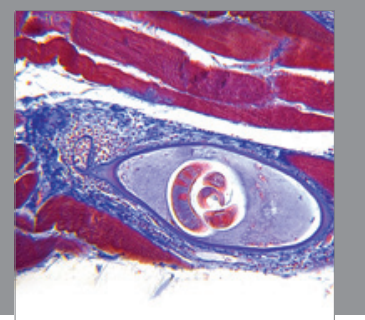

Gastroenterology

Research and Practice
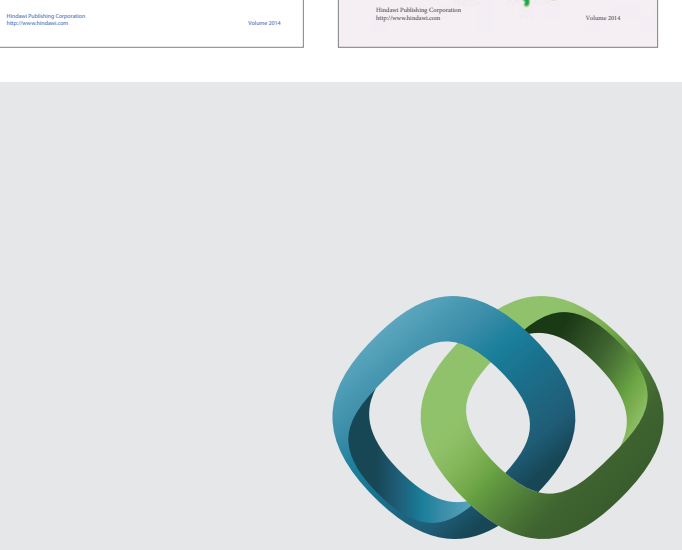

\section{Hindawi}

Submit your manuscripts at

http://www.hindawi.com
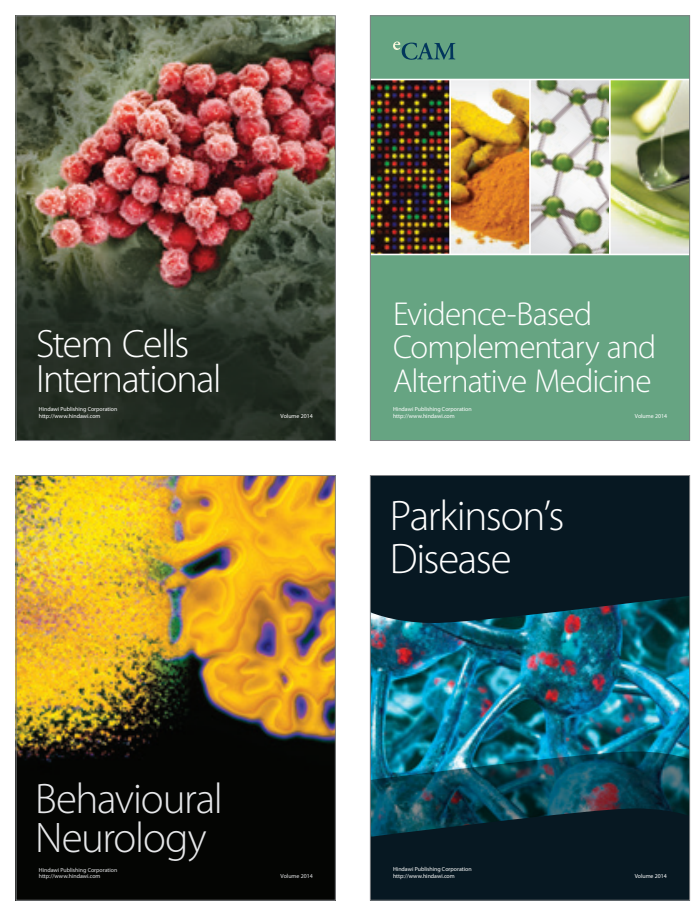

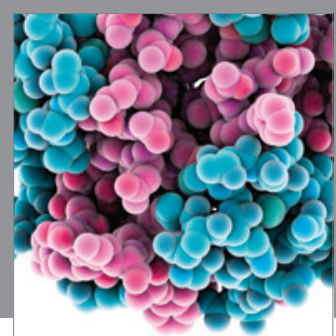

Journal of
Diabetes Research

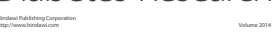

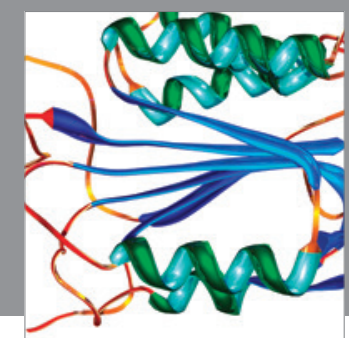

Disease Markers
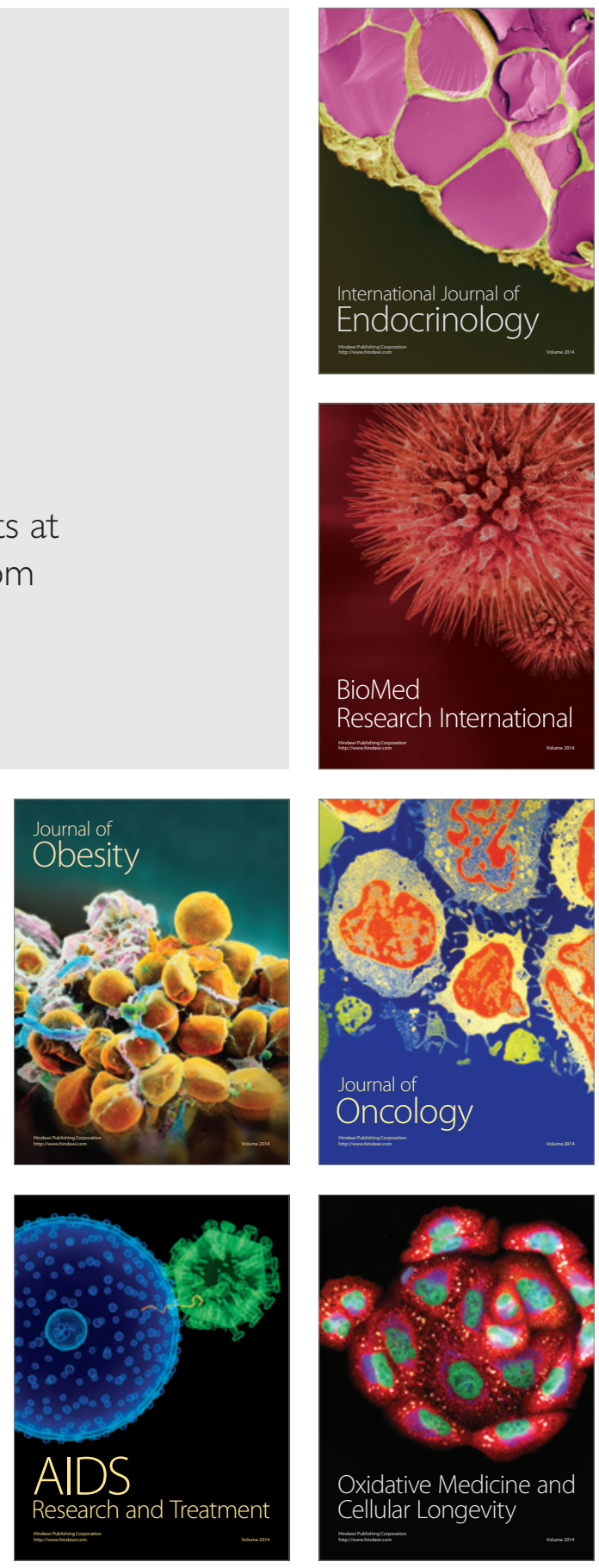